\title{
Hydromechanical signaling between the ciliate Mesodinium pulex and motile protist prey
}

\author{
H. H. Jakobsen ${ }^{1,2, *}$, L. M. Everett ${ }^{1}$, S. L. Strom $^{1}$ \\ ${ }^{1}$ Western Washington University, Shannon Point Marine Center, 1900 Shannon Point Road, Anacortes, Washington 98221, USA \\ ${ }^{2}$ Present address: Danish Institute for Fisheries Research, Dept. of Marine Ecology and Aquaculture, Kavalergården 6, \\ 2920 Charlottenlund, Denmark
}

\begin{abstract}
The raptorial ciliate Mesodinium pulex (Claparéde \& Lachmann, 1858) was fed 3 different prey species: Rhodomonas salina, Heterocapsa rotundata and Gymnodinium simplex. Each prey displayed different motility patterns, including dramatic and effective escape responses. $M$. pulex only fed while motionless and responded only to motile prey by either an attack or an escape. Both the attack and escape responses are associated with a strong directional component in M. pulex. $M$. pulex responded to motile prey when the critical fluid velocity exceeded $\sim 15$ to $42 \mu \mathrm{m} \mathrm{s}^{-1}$, depending on prey species. These values are similar to hydromechanical signal thresholds found in marine metazoans. Prey-induced escape responses in M. pulex are associated with fast-swimming prey such as G. simplex. Deformation rates calculated in these specialized cases exceed the reported critical deformation rate for escape in ciliated protists, suggesting that fast-swimming prey mimic an approaching predator. Microscopic observations indicate that the band of equatorial cirri encircling $M$. pulex is the principal detector of motile prey. We propose that $M$. pulex exhibits a specialized fluid velocity-sensitive mechanoreceptor analogous to the fluid motion mechanoreceptors found in metazoans. M. pulex fails to ingest the cryptophytic prey $R$. salina. Our observations suggest that this is due to mismatch between the capturing organelles of the ciliate and surface properties of the prey. Dinoflagellate prey are more effectively ingested, but a high percentage escaped from M. pulex. Pre-capture escape responses may be triggered by ciliate-generated hydromechanical signals and facilitated by the strong swimming ability of the flagellates. Hydromechanical signaling can affect the outcome of predator-prey interactions and may select for distinctive morphological and behavioral features in planktonic protists.
\end{abstract}

KEY WORDS: Sensory ecology · Hydrodynamical signals · Escape behavior · Predator avoidance · Protist-protists interactions · Microzooplankton

\section{INTRODUCTION}

Ciliates and heterotrophic dinoflagellates are among the most important consumers of phytoplankton in the ocean (Stoecker \& Capuzzo 1990, Strom 2002). Freeliving planktonic heterotrophic protists, such as ciliates and dinoflagellates, can detect prey chemically (e.g. Fenchel \& Jonsson 1988, Verity 1991). By adapting swimming behaviors, such as swimming speed and turning rate, protists are able to translate along chemical gradients and aggregate around food patches (e.g. Fenchel \& Jonsson 1988, Buskey \& Stoecker 1989, Fenchel \& Blackburn 1999). In contrast, swimming increases encounters with predators (Tiselius et al. 1997, Jakobsen et al. 2005), and low motility or even motionless feeding behavior may be a way to reduce predation. There is thus an apparent trade-off in the value of motility, as swimming increases encounters with food, but also with predators.

Members of the genus Mesodinium such as M. pulex are raptorial ambush predators, i.e. they remain motionless until encountered by a motile prey. This feeding behavior does not allow translation along chemical gradients, so detection of individual prey cells must be governed by an alternative signal, such as the hydromechanical signals generated by prey 
motion. Adaptations that permit remote detection of prey by hydromechanical signals are known from metazoans (Feigenbaum \& Reeve 1977, Kerfoot 1978). In protists, mechanical detection of prey has been reported for the interception-feeding ciliate Favella sp. (Buskey \& Stoecker 1989). However, mechanical prey detection in that case appeared to require direct physical contact between the oral region of Favella sp. and its prey (Stoecker et al. 1995).

Saltatory swimming behavior in ciliated protists is well described in the literature (Tamar 1965). Saltatory behavior seems to be somehow linked to the ability to remotely detect and evade predators (e.g. Jonsson \& Tiselius 1990, Gilbert 1994). Fluid motion generated by predators at low Reynold's number ( $R e$ ) is detected as cell body deformation in rheotactic saltatory ciliates (Jakobsen 2001). One of the most common biological sources of fluid deformation encountered by freeliving protists is feeding currents generated by predatory metazoans. In a feeding current, the prey cell is strained along a fluid velocity gradient, and it responds when the strain reaches a well-defined deformation rate threshold of about $3 \mathrm{~s}^{-1}$ (Jakobsen 2001, 2002). The response is an immediate avoidance reaction that can transport the cell out of danger (Tamar 1965, Jonsson \& Tiselius 1990, Gilbert 1994).

The transmission and detection of fluid mechanical signals between protists is, however, poorly understood. Here, we identified and quantified a novel fluid mechanical mechanism for remote prey detection in the raptorial ciliate Mesodinium pulex. We also identified remote fluid mechanical capabilities of predator detection in small flagellates that strongly influence their ability to avoid ciliate predation. These capabilities suggest that interactions among free-living protists are governed, in part, by the exchange of hydromechanical signals between prey and predators.

\section{MATERIALS AND METHODS}

Experimental conditions. Stock cultures of ciliates and prey were maintained in a climate-controlled cabinet at $15^{\circ} \mathrm{C}$. All live cultures were maintained in prefiltered $(0.2 \mu \mathrm{m})$ autoclaved seawater with added $f / 2$ nutrients (omitting $\mathrm{Si}$ ). Illumination was provided from fluorescent daylight bulbs in a 14:10 h light:dark cycle.

Ciliate culture. The ciliate was isolated from water samples collected from a boat launch near Shannon Point Marine Center, Washington, USA. Based on the description given by Tamar (1992), we identified our iso- late as Mesodinium pulex. This ciliate has a strong affinity for small dinoflagellate prey (Tang et al. 2001). Adding small amounts of the autotrophic dinoflagellate Heterocapsa rotundata to raw seawater yielded positive growth of $M$. pulex within a few weeks. Pure cultures of $M$. pulex were established by pipetting single cells into $3 \mathrm{ml}$ micro-wells containing autoclaved seawater and $H$. rotundata as prey. Stock cultures were maintained on a slowly rotating plankton wheel at an irradiance of $50 \mu \mathrm{mol}$ photons $\mathrm{m}^{-2} \mathrm{~s}^{-1}$.

Phytoplankton culture. Phytoplankton stock cultures were grown at an irradiance of 70 to $100 \mu \mathrm{mol}$ photons $\mathrm{m}^{-2} \mathrm{~s}^{-1}$. The prey species used were 2 dinoflagellates and 1 cryptophyte, namely Gymnodinium simplex (CCMP 418), Heterocapsa rotundata (K-483, SCAP) and Rhodomonas salina (Marine Biological Laboratory, University of Copenhagen), respectively. Prey size increased in the order $R$. salina $<H$. rotundata $<G$. simplex (Table 1). However, only $R$. salina and G. simplex differed significantly in size (Tukey's $t$-test $\mathrm{p}=0.028$ ). These 3 flagellates each display characteristic modes of swimming. When detecting hydromechanical signals at protist size scales, however, only swimming speed and prey cell size matter (Visser 2001, Jakobsen et al. 2005).

Video recordings. Predator-prey encounters were observed under an inverted Olympus CK2 microscope in $50 \mathrm{ml}$ transparent Nunclon tissue flasks (NUNC A/S Denmark, www.nuncbrand.com) at temperatures close to $15^{\circ} \mathrm{C}$ and within $30 \mathrm{~min}$ after the cultures were removed from the culture cabinet. Observations were conducted in bright field illumination using the standard illumination of the microscope. The basic focal depth of the optics used is roughly $6 \mu \mathrm{m}$ according to the microscope specifications, but, by adjusting the microscope illumination apparatus, we increased the focal depth to around 1 Mesodinium pulex cell radius $(\sim 10 \mu \mathrm{m})$. Because we assumed cirri to be the principal detectors of prey motility, the microscope focal plane was held constant in the plane of the cirri during videorecordings.

Mesodinium pulex has an affinity for surfaces and is considered a semi-benthic species. Cells scanning for prey were observed in an inverted microscope, either
Table 1. Cell sizes of experimental organisms. Dimensions $(\mu \mathrm{m})$ were obtained from digitized images captured from video recordings. ESD: equivalent spherical diameter; numbers in parentheses: $1 \mathrm{SD} ; \mathrm{N}$ : number of observations

\begin{tabular}{|cccccc|}
\hline ESD & $\begin{array}{c}\text { Mesodinium pulex } \\
\text { Cirri length }\end{array}$ & Cell length & $\begin{array}{c}\text { Heterocapsa } \\
\text { rotundata } \\
\text { ESD }\end{array}$ & $\begin{array}{c}\text { Gymnodinium } \\
\text { simplex } \\
\text { ESD }\end{array}$ & $\begin{array}{c}\text { Rhodomonas } \\
\text { salina } \\
\text { ESD }\end{array}$ \\
\hline $18(3)$ & $5.4(1.2)$ & $22(4)$ & $\begin{array}{c}8.6(1.3) \\
\mathrm{N}=22\end{array}$ & $\begin{array}{c}9(2.3) \\
\mathrm{N}=25\end{array}$ & $\begin{array}{c}7(3) \\
\mathrm{N}=13\end{array}$ \\
$\mathrm{~N}=60$ & $\mathrm{~N}=60$ & $\mathrm{~N}=60$ & $\mathrm{n}$ & & \\
\hline
\end{tabular}


motionless or drifting slowly above the bottom of the tissue flask. In this fashion individual encounters between the ciliate $M$. pulex and the various prey could easily be observed and video-recorded for later motion analysis. We video-recorded swimming prey cells in encounters with $M$. pulex and calculated the components of the associated fluid signal.

A charge coupled device (CCD) B/W standard surveillance video camera connected to a video-tape recorder was used to record swimming trajectories. Analogue video sequences, including encounter events, were converted into QuickTime digital movies using a video capture card (Videum capture 1000, Winnov) for further analysis. Motion analyses of individual swimming trajectories from the digital movies allowed us to estimate individual swimming speeds and were conducted using frame-by-frame tracking of individual prey particles at rates of 30 frames $\mathrm{s}^{-1}$ with an automated motion analysis software package (Labtrack by Bioras, www.bioras.com/). Observations in 2D underestimate length scales, which, in turn, underestimate swimming velocities and reaction distances. To minimize this error, we only considered cells that were translating in the focal plane. This allowed us to follow prey cells for a while before they encountered Mesodinium pulex. The observational time scale before an encounter with $M$. pulex depended on the prey swimming speed. However, on average, we followed Rhodomonas salina for $1.3 \mathrm{~s}$, Gymnodinium simplex for $0.6 \mathrm{~s}$ and Heterocapsa rotundata for $1.3 \mathrm{~s}$. These observational time periods allowed us, on average, to follow the prey ca. $190 \mu \mathrm{m}$ or ca. 20 body lengths.

In addition to determining swimming speeds of individual prey cells before, during and after encounters with Mesodinium pulex, we quantified behavioral components by metric analysis of individually digitized video frames using Sigma Scan Pro 5.0 image analysis software (SPSS). From these images we determined behavioral parameters, such as reaction distances, attack and avoidance angles of predators and the critical fluid velocity. The reaction distance was estimated as the shortest distance from the center of mass of the motile prey to the outer cell surface of the ciliate. Cell dimensions were estimated from individually digitized video frames using Sigma Scan Pro image analysis software, and cell volumes were calculated assuming prey cells as prolate spheroids and $M$. pulex as a sphere.

Quantification of protist behavioral responses. Prey cell behavior was quantified by dividing predator-prey encounters into 5 categories (see Table 4). Category 1, the ciliate detects the motile prey; Category 2 , the prey escapes, either by changing swimming direction or increasing swimming volocity; Category 3, successful captures of prey by Mesodinium pulex, referring to a temporary immobilization of the prey; Category 4, post-capture escapes, the prey either being rejected or actively escaping $M$. pulex. We also calculated the ingestion efficiency as the ratio of ingested prey to detected prey, and termed this Category 5. In encounters between the 2 dinoflagellate prey species and $M$. pulex, successful capture was defined as fixation of the prey to the oral tentacles. Because $M$. pulex was unable to fix the cryptophyte Rhodomonas salina to its tentacles, successful capture in this case was equated with a temporary paralyzing of the prey cell.

Calculation of signal values. Organisms and particles swimming or sinking through water in a viscous environment create hydromechanical disturbance. The strength of these disturbances depends on the size of the moving particle and its speed relative to the surrounding fluid, which decrease exponentially with distance $r$ away from the moving body. The signal strength varies according to the angle $\theta$ to the principal axis of swimming direction. This was described mathematically for a self-propelled particle by a 'dipole'shaped stresslet model by Visser (2001):

$$
U_{r}=\frac{3}{2} \frac{U a^{2}}{r^{2}}\left(1-3 \cos ^{2} \theta\right)
$$

and is illustrated by the fluid disturbance lines shown surrounding the prey cell in Fig. 1. In terms of calculating the critical fluid velocity for a response in the ciliate Mesodinium pulex, $U_{r}$ is the fluid velocity at the reaction distance $r$ from the center of mass of the prey to the surface of the ciliate, $a$ is the prey diameter, $U$ is the prey swimming velocity and $\theta$ is the angle between the principal axis of swimming of the prey cell and the vector between the mass centers of the ciliate and the prey. The sizes of the prey and the ciliate, the reaction distance $r$ and $\theta$ are estimated from individually digitized video frames. These values were used for each individual encounter to estimate the critical fluid velocity that elicited a response in $M$. pulex.

\section{RESULTS}

\section{Ciliate morphology and behavior}

Mesodinium pulex has a spheroid body equatorially ringed by a number of cirri and membranelles (Fig. 1). The membranelles are fused to the cell body below the cirri and are used in locomotion. In motionless feeding they curve with the body and extend almost to the posterior end of the cell. According to Tamar (1992) there are an equivalent number of cirri and membranelles. The oral structure forms a unique barrel-shaped proboscis (Fig. 1). It consists of a circum-oral ring of cilia- 

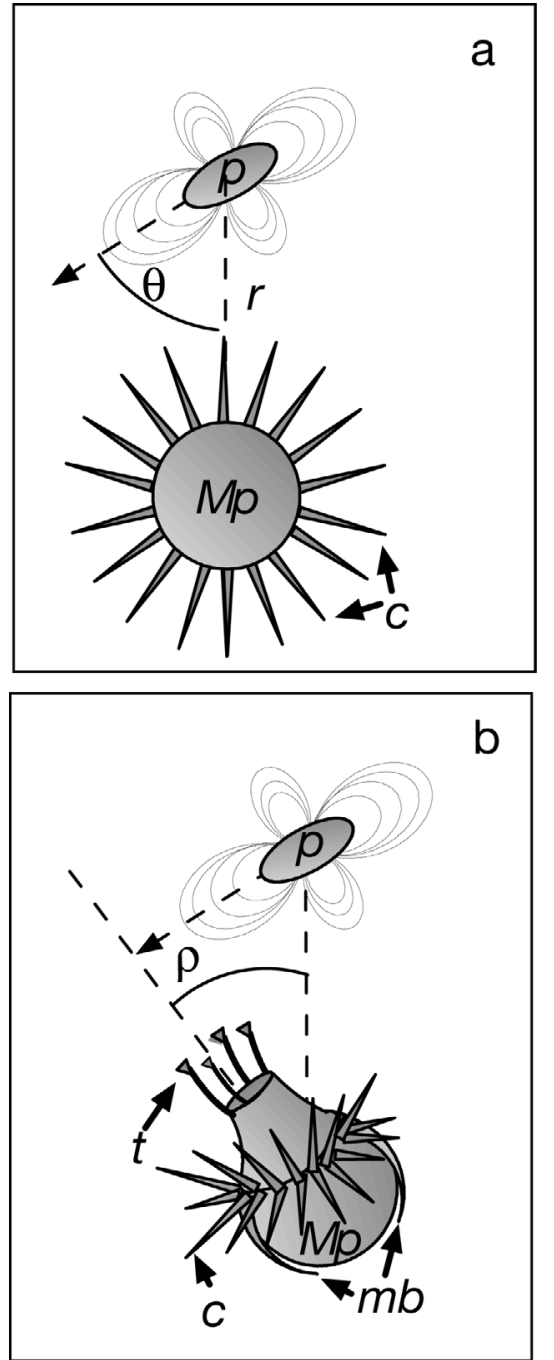

Fig. 1. Overview of the relevant components, including vectors and angles, used to describe encounters between Mesodinium pulex $(M p)$ and its prey. The motile prey $(p)$ is surrounded by conceptual flow disturbance isoclines. (a) Video frame prior to attack by $M$. pulex. The ciliate is viewed from the anterior-posterior direction. The prey approaches the motionless ciliate cell that drifts, neutrally buoyant, with the proboscis oriented towards gravity. Note the equatorial cirri (c) that are bent differentially by the fluid disturbance field, depicted with isoclines surrounding the motile prey. The angle $(\theta)$ is the angle between the principal axis of the swimming prey and the line drawn between the centers of mass of the 2 interacting organisms. The reaction distance (line marked $r$ ) is the distance between the prey and predator cell body surfaces. (b) Response by M. pulex 1 frame $(1 / 30 \mathrm{~s})$ later, viewed in the same plane as in (a). The ciliate rapidly orients its proboscis and tentacles $(t)$ toward the prey in a capture attempt and is hence viewed in the medial plane. The response angle $(\rho)$ is the angle between the principal axis of the longitudinally oriented ciliate cell and the reaction distance vector $r . \rho$ can range from $0^{\circ}$ (ciliate oriented directly toward prey) to $180^{\circ}$ (ciliate oriented directly away from prey). The membranelles $(\mathrm{mb})$ are used in locomotion, including reorientation of the ciliate cell, but here are shown in their resting position like tentacles that extend longitudinally away from the barrel and end in small triangular plates or 'globose endings'. The oral structure was described in detail and termed the 'tentacular process' by Tamar (1992). During prey capture, $M$. pulex attempted to fix the prey to the small triangular plates, which appeared to be sticky. Prey cells, once successfully captured, remained fixed to these triangular plates for a certain length of time before ingestion.

During our observations, the ciliates remained motionless, drifting with background advection, while waiting in ambush for prey. Motionless drifting was occasionally interrupted by helical swimming, allowing translocation between patches of prey cells. Prey motion seemed to be required to initiate a predation response by Mesodinium pulex. We sometimes observed prey cells laying motionless on the bottom surface of a tissue flask. When neutrally buoyant $M$. pulex were advected past such motionless prey cells, no response in either the ciliate or the prey was observed.

Once swimming prey were within striking distance (0.5 to 1.5 prey cell lengths - see reaction distances in Table 2), the ciliate responded in nearly all (92 to $100 \%$ ) of the recorded encounters. The response, in which $M$. pulex orients its proboscis towards the prey (Fig. 1b), was dramatic and rapid, requiring only 1 to 2 video frames (0.033 to $0.066 \mathrm{~s})$. A video clip of the response can be viewed online as supplementary material; see Video 1, available at: www.int-res.com/ articles/suppl/a044p197_videos/. The orientation of the oral apparatus toward the prey led to 1 of 2 reactions in the ciliate: either the ciliate attempted to capture the prey or the ciliate responded with a reverse 'escape' swim. The response to swimming prey depended on prey species, such that a higher proportion of $M$. pulex exhibited escape behavior when the approaching prey was the fastest-swimming species, Gymnodinium simplex (Table 2).

Regardless of the prey species, the majority of prey capture attempts were unsuccessful, due to prey avoidance and escape behaviors (see below). A successful capture of Heterocapsa rotundata by Mesodinium pulex resulted in a series of short reversals in the ciliate of about 2 to 4 body lengths. During reversals the prey was swallowed through the proboscis; the capture and handling time varied between 1.2 and $7.1 \mathrm{~s}(\bar{x}=2.7 \mathrm{~s} \pm$ $2 \mathrm{SD}, \mathrm{N}=9$ ) for $H$. rotundata (Video 2, www.int-res.com/ articles/suppl/a044p197_videos/). When M. pulex attacked Rhodomonas salina, the flagellate appeared immobilized for a short while. During immobilization, $R$. salina wriggled without moving forwarded or backwards, suggesting that the cell had become temporarily incapacitated by its encounters with the ciliate (Video 3, www.int-res.com/articles/suppl/a044p197_videos/). After about $1 \mathrm{~s}(\bar{x}=1 \pm 1.2 \mathrm{SD}, \mathrm{N}=5)$ the immobilization effect 
Table 2. Prey swimming velocities before encounters with the ciliate Mesodinium pulex that resulted in a ciliate response. $M$. pulex responded either with attack or escape behavior, depending on prey velocity. The reaction distances of $M$. pulex in encounters with the different prey were measured from single frames. No statistical differences between prey species and reaction distances were identified (1-way ANOVA). Mean response angles of $M$. pulex to approaching prey were calculated according to Batchelet (1981). N: number of observations

\begin{tabular}{|c|c|c|c|}
\hline & $\begin{array}{l}\text { Heterocapsa } \\
\text { rotundata }\end{array}$ & $\begin{array}{l}\text { Gymnodinium } \\
\text { simplex }\end{array}$ & $\begin{array}{l}\text { Rhodomonas } \\
\text { salina }\end{array}$ \\
\hline $\begin{array}{l}\text { Approaching swimming speed, } \\
\mu \mathrm{m} \mathrm{s}^{-1} \text { (geometric mean, } \pm 1 \mathrm{SD} \text { ) }\end{array}$ & $\begin{array}{l}102(34) \\
N=22\end{array}$ & $\begin{array}{l}234(34) \\
\mathrm{N}=25\end{array}$ & $\begin{array}{l}153(16) \\
\mathrm{N}=13\end{array}$ \\
\hline $\begin{array}{l}\text { Escape swimming speed, } \mu \mathrm{m} \mathrm{s}^{-1} \\
\text { (arithmetic mean, 95\% } \\
\text { confidence limits) }\end{array}$ & $\begin{array}{c}564(14) \\
\mathrm{N}=14\end{array}$ & $\begin{array}{c}879(39) \\
N=25\end{array}$ & $\begin{array}{l}950(90) \\
\mathrm{N}=5\end{array}$ \\
\hline $\begin{array}{l}\text { Mesodinium pulex attack, } \\
\% \text { of total observations }\end{array}$ & 95 & 60 & 85 \\
\hline $\begin{array}{l}\text { Mesodinium pulex escape, } \\
\% \text { of total observations }\end{array}$ & 5 & 40 & 15 \\
\hline $\begin{array}{l}\text { Reaction distance } r, \mu \mathrm{m} \\
( \pm 1 \mathrm{SD})\end{array}$ & $\begin{array}{l}10(4) \\
\mathrm{N}=22\end{array}$ & $\begin{array}{l}12(6) \\
N=25\end{array}$ & $\begin{array}{l}13(5) \\
N=13\end{array}$ \\
\hline $\begin{array}{l}\text { Mean response angle of } \\
\text { M. pulex ( } \pm \text { angular deviation) }\end{array}$ & $\begin{array}{c}21^{\circ}\left( \pm 28^{\circ}\right) \\
\mathrm{N}=22\end{array}$ & $\begin{array}{c}33^{\circ}\left( \pm 40^{\circ}\right) \\
\mathrm{N}=25\end{array}$ & $\begin{array}{l}22^{\circ}\left( \pm 41^{\circ}\right) \\
\mathrm{N}=13\end{array}$ \\
\hline
\end{tabular}

seemed to wear off and $R$. salina either jumped or swam away.

Attacks were observed when the average critical fluid velocity generated by the approaching prey exceeded 15 to $42 \mu \mathrm{m} \mathrm{s}^{-1}$ at the base of the cirri (Table 3). In the case of encounters with the fast-swimming dinoflagellate Gymnodinium simplex, the ciliate 'escaped' in ca. $40 \%$ of the predator-prey encounters. The critical fluid velocity calculated separately for these encounters averaged $95 \mu \mathrm{m} \mathrm{s}^{-1}$ (Table 3).

Regardless of whether Mesodinium pulex ultimately attacked or escaped, once prey were detected, the oral apparatus was always oriented towards the prey. The response angle $\rho$ is the angle between the principal axis of the longitudinally oriented ciliate cell and the reaction distance vector $r$. $\rho$ was estimated from the geomet-

Table 3. Average critical fluid velocity $\left(\mu \mathrm{m} \mathrm{s} \mathrm{s}^{-1}\right)$ for prey detection for all encounters with the 3 prey organisms calculated from Eq. (1), using appropriate values extracted from motion analysis of QuickTime clips (see www.intres.com/articles/suppl/a044p197_videos/) and individually grabbed video frames. Numbers in parentheses: $\pm 95 \%$ confidence limits

\begin{tabular}{|lcc|}
\hline Prey species & $\begin{array}{c}\text { Predator } \\
\text { response }\end{array}$ & $\begin{array}{c}\text { Critical fluid } \\
\text { velocity }\end{array}$ \\
\hline Heterocapsa rotundata & Attack & $32(3.1)$ \\
Rhodomonas salina & Attack & $15(1.1)$ \\
Gymnodinium simplex & Attack & $42(6.5)$ \\
Gymnodinium simplex & Escape & $95(7.3)$ \\
\hline
\end{tabular}

ric relationship between the principal axis of the attacking ciliate and the reaction distance vector. Angular statistics were calculated according to Batchelet (1981) (Table 2, Fig. 2).

The focal depth $(f d)$ of $10 \mu \mathrm{m}$ also affected the reaction distance estimate. However, assuming that the prey moved isotropically along the focal plane, our observation potentially could be in error by a factor of $f d / 2$. The error in estimates of the linear dimensions of $r$ associated with this $\left(r^{\prime}\right)$ can be calculated as $r^{\prime}=\sqrt{\left[r^{2}+(f d / 2)^{2}\right]}$. Hence, for a reaction distance of $10 \mu \mathrm{m}, r^{\prime}=$ $11 \mu \mathrm{m}$, which, in turn, changes the estimate of $U_{r}$. For a particle with a diameter of $10 \mu \mathrm{m}$ swimming at $150 \mu \mathrm{m} \mathrm{s}^{-1}, U_{r}$ computed from $r^{\prime}$ is $\pm 13 \%$ of that computed for a reaction distance of $10 \mu \mathrm{m}$.

When the ciliate 'escaped' from the prey, it swam 'backwards' with the tentacular apparatus facing the prey. However, attempts to quantify escape lengths failed mainly because of the limited observational length scale in the current experimental set up.

\section{Prey behavior}

Prey swimming speeds were divided into 2 groups (Table 2): approaching speed prior to encounter with Mesodinium pulex and post-encounter reversal swimming speed. The orientation of the ciliate oral apparatus toward the prey during encounter initiates a short, strong hydromechanical pulse that potentially warns the prey of an impending attack. All the studied prey species were able to increase swimming velocities by a factor of 3 to 5 upon encountering the motionless predatory $M$. pulex. The 2 dinoflagellates responded immediately prior to physical contact with the ciliate. The cryptophyte Rhodomonas salina needed to be attacked by $M$. pulex and handled in order to display escape behavior. Although they differed, both dinoflagellate and cryptophyte escape behaviors were highly effective, leading to low ingestion efficiencies on $R$. salina and Gymnodinium simplex. However, the ingestion efficiency on $H$. rotundata was significantly higher: this prey species was engulfed in $25 \%$ of all encounters $\left(\chi^{2}\right.$-test, $\left.\mathrm{p}=0.05\right)$ (Table 4$)$.

The avoidance response in all 3 prey types consisted of an immediate reversal followed by a tumble succeeded by normal swimming. We tested the response frequencies of prey species using a pair-wise $\chi^{2}$-test. The dinoflagellates responded similarly in almost every 

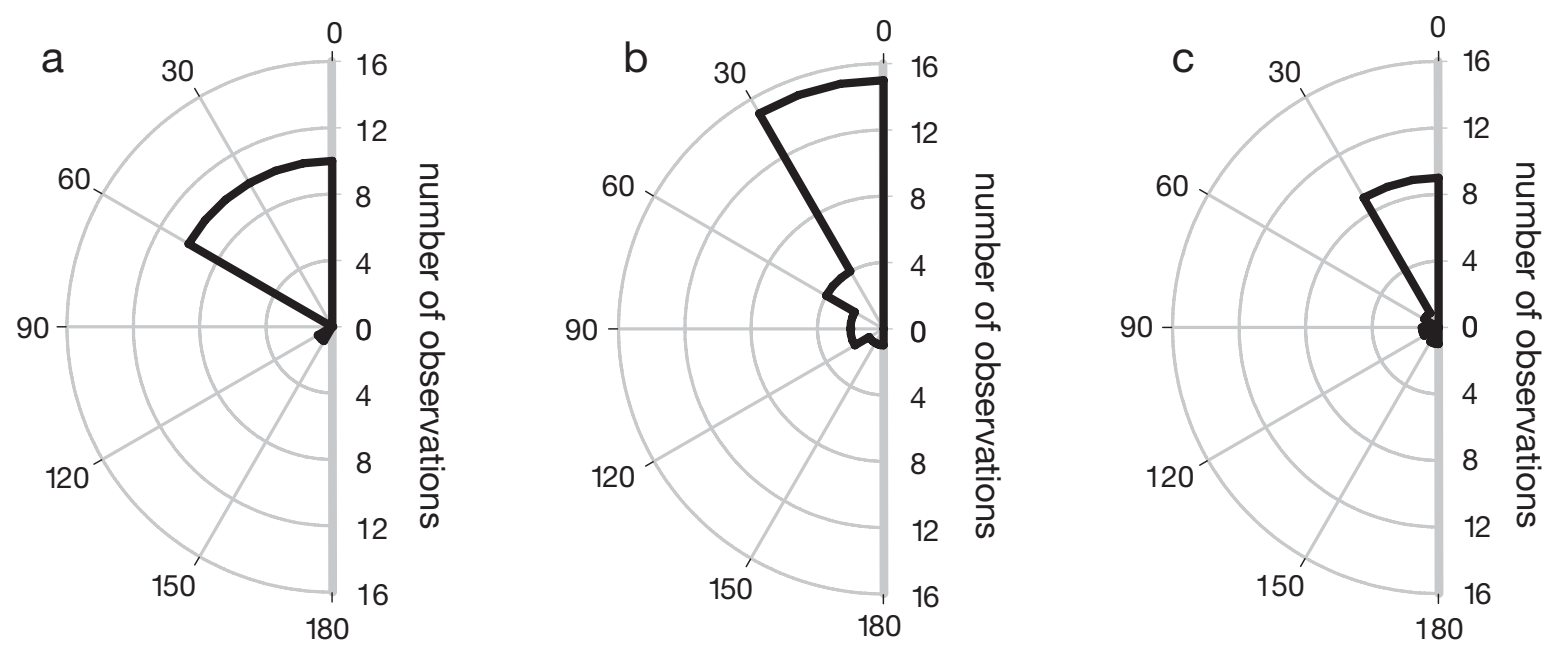

Fig. 2. Horizontal response of Mesodinium pulex to 3 approaching prey species: (a) Heterocapsa rotundata; (b) Gymnodinium simplex and (c) Rhodomonas salina

case except in Category 3 (successful captures of prey by Mesodinium pulex; Table 4). The faster-swimming Gymnodinium simplex was more successful than Heterocapsa rotundata at avoiding capture by $M$. pulex (capture success 4 vs. $30 \%$ ), in part because G. simplex triggered a high frequency of escape behaviors in the ciliate predator (Table 2). In comparison with the dinoflagellates, a significantly smaller fraction of Rhodomonas salina detected and escaped the predatory ciliate prior to being attacked $\left(\chi^{2}\right.$-test, $\left.\mathrm{p}=0.05\right)$, and a high proportion of the encounters $(62 \%)$ led to temporary immobilization of $R$. salina (Table 4). Successful capture of $R$. salina by M. pulex refers to temporary immobilization. In contrast to the dinoflagellates, the cryptophyte was never fixed to the oral apparatus of

Table 4. Encounters between Mesodinium pulex and its prey divided into 5 categories (see 'Materials and methods; Quantification of protist behavioral responses'). Ingestion efficiency is calculated as the total number of prey ingested over the number of detected prey. No $R$. salina were ingested. Values were normalized to the total number of encounters observed. N: number of observations; ${ }^{*}$ : observations statistically different from expected values $\left(\chi^{2}\right.$-test, $\left.p=0.5\right)$

\begin{tabular}{|lcccc|}
\hline Category Event & $\begin{array}{c}\text { Heterocapsa } \\
\text { rotundata } \\
(\mathrm{N}=37)\end{array}$ & $\begin{array}{c}\text { Gymnodinium } \\
\text { simplex } \\
(\mathrm{N}=24)\end{array}$ & $\begin{array}{c}\text { Rhodomonas } \\
\text { salina } \\
(\mathrm{N}=13)\end{array}$ \\
\hline $1 \quad \begin{array}{c}\text { M. pulex detect motile } \\
\text { prey (\%) }\end{array}$ & 97 & 100 & 92 \\
$2 \quad \begin{array}{c}\text { Motile prey detect and } \\
\text { perform escape response } \\
\text { away from M. pulex (\%) }\end{array}$ & 76 & 79 & $15^{*}$ \\
$3 \quad \begin{array}{c}\text { Successful captures of prey } \\
\text { by M. pulex (\%) }\end{array}$ & 30 & $4^{*}$ & 62 \\
4 & $\begin{array}{c}\text { Post-capture escapes (\%) } \\
\text { Ingestion efficiency (\%) }\end{array}$ & 5 & 0 & $31^{*}$ \\
\hline & $25^{*}$ & 4 & 0 \\
\hline
\end{tabular}

M. pulex. Instead, R. salina was pushed forward by the ciliate in a series of attack 'darts' in an attempt to fix the prey to its oral apparatus. No G. simplex and few H. rotundata managed to escape $M$. pulex once captured, while a significantly higher proportion of $R$. salina $\left(31 \%, \chi^{2}\right.$-test, $\left.\mathrm{p}=0.05\right)$ jumped away after being immobilized for about $1 \mathrm{~s}( \pm 1.2 \mathrm{SD}, \mathrm{N}=6)$.

\section{DISCUSSION}

\section{Motionless predator detection of motile prey}

Ciliates that utilize chemical cues in their food detection move up or down prey-generated chemical gradients (Fenchel \& Blackburn 1999). In the absence of motility, as is the case for the ambush-feeding Mesodinium pulex, no chemical gradient can be detected by the predator, and it is therefore less likely that prey-emitted chemicals are involved in prey detection by this species. Detection of preygenerated fluid mechanical signals is a plausible signal entity.

The predator-prey interactions reported here occurred at length scales where viscous forces are much more important than inertial forces (low Re). At these scales the fluid disturbance generated by a self-propelled body can be modeled by a dipole-shaped stresslet (Eq. 1, Visser 2001). Eq. (1) predicts that, for cells of uniform size, swimming velocity is the governing parameter determining the fluid mechanical signal. 
Depending on the sizes and velocities of the 2 interacting organisms, the signaling quantity can be either fluid velocity or deformation rate. When the detector is much larger than the moving body, the velocity at the outer periphery of the detector, closest to the moving body, is much larger than the 'virtual fluid velocity' (the fluid velocity had the detector not been there) at the center of mass (COM) of the detector. That is, the peripheral sensors in the vicinity of the moving particle are bent spatially by the fluid motion, while the COM further away is moved minimally and appears 'anchored' (Fig. 3a). In this case the detectable signal is set by the absolute fluid velocity at the peripheral sensor (Kiørboe \& Visser 1999). However, if the detector is much smaller than the moving body, the virtual fluid velocity at the COM of the detector is close to that at the peripheral sensor in the vicinity of the approaching body. Because the entire detector body is moved, a fluid velocity gradient or 'shear rate' across the detector body is the relevant hydromechanical signaling quantity (Fig. 3b).

The case in which Mesodinium pulex is encountered by small motile prey is an example of a large detector being encountered by a small self-propelled detectee (Fig. 3a). The virtual velocity at the COM of M. pulex is much less than the fluid velocity at the peripheral cirri close to the approaching prey; thus, the fluid velocity difference between the peripheral cirri and the COM of the ciliate is large and the absolute fluid velocity at the cirri is the appropriate signal.

The equatorial cirri are held fixed in a pattern forming a 3D array around the cell body of Mesodinium pulex. This arrangement appears to be a functional analogue of the setae on copepod antennae (see Fig. 1). In copepods the sensory setae are typically fixed on the first antennae. The setae are bent relative to fluid motion generated by prey, allowing spatial and temporal localization of prey. Encounters between $M$. pulex and its prey may present a similar scenario, in which the approaching prey bends the cirri in a differential fashion. As the prey approaches the ciliate, the fluid velocity gradient will bend the cirri in a manner determined by the velocity and swimming direction of the prey (Table 3). Differential bending of the cirri yields a high information content that can be used to identify prey size, prey swimming velocity and the spatial location of the prey. The response orientation of $M$. pulex to the prey is precise (Fig. 2) and offers further support for the hypothesis that bending of the cirri by differentially moving fluid is the pertinent signal in encounters between $M$. pulex and its prey. Once detected, reactions to motile particles are either by attack or by an evasive, escape-like reaction.

Mechanoreception in ciliates is linked to cell membrane potential (Naitoh \& Eckert 1969). However, examples of motor control governed by specialized cirri have been shown for the ciliates Paramecium, Stylonychia and Euplotes spp. (De Peyer \& Machemer 1978, Görtz 1982, Machemer \& Machemer-Röhnisch 1984); furthermore, it has been suggested that such specialized cirri are rooted through specialized basal bodies to cell membrane sites with elevated sensitivity (Machemer \& Deitmer 1985). This is in agreement with TEM imagery of the congeneric Mesodinium rubrum.
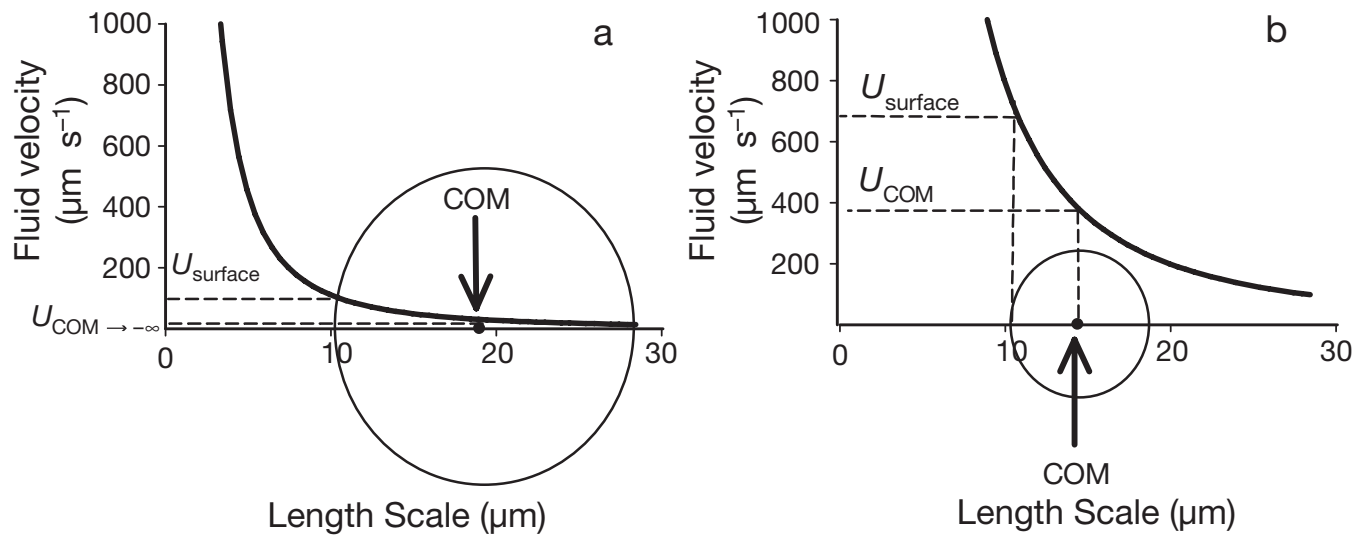

Fig. 3. Detection of fluid mechanical signals generated by motile particles at the life scales of planktonic protists. The reaction distance is $10 \mu \mathrm{m}$, similar to the reaction distance between Mesodinium pulex and Heterocapsa rotundata. Curved line represents the fluid velocity at distance $r(\mu \mathrm{m})$ in front of a moving object and was calculated using Eq. (1). (a) A detector the size of $M$. pulex detecting a motile particle the size of $H$. rotundata swimming at $200 \mu \mathrm{m} \mathrm{s}^{-1}$. The fluid velocity difference $(\Delta U)$ between the peripheral sensors $\left(U_{\text {surface }}\right)$ and the center of mass $(C O M)$ is large, and the detector appears to be anchored, while the fluid motion generated by the translating small particle moves by the peripheral sensors $\left(U_{\mathrm{COM}} \rightarrow-\infty\right)$. In this case, the virtual velocity at the COM is infinitely small and $\Delta U=U_{\text {surface }}$ because $U_{\mathrm{COM}} \rightarrow-\infty$. (b) A small detector the size of $H$. rotundata detecting a motile particle the size of $M$. pulex swimming at $200 \mu \mathrm{m} \mathrm{s}^{-1}$. The velocity difference between the periphery and the COM is small, and the COM is moved by the fluid motion. That is $\Delta U=U_{\text {surface }}-U_{\mathrm{COM}}$. Movement of the COM creates shear stress across the entire cell body, which is detected by $H$. rotundata as deformation rate 
In $M$. rubrum the equatorial cirri were interconnected in the cell membrane by a system of fibers linked to a common striated fiber band (Lindholm et al. 1988). Our microscopic observations indicated that the equatorial cirri were held completely fixed and motionless while M. pulex were scanning for prey, allowing optimal transduction of ambient fluid motion to sensory sites in the cell membrane. This suggests that perception of prey is conducted separately by cirri, while motility is carried out by beating of the membranelles in $M$. pulex. In a few observations where the prey was moving slowly, the ciliate appeared unable to detect the prey remotely. Instead the prey was able to move in very close to the ciliate, which responded only when the equatorial cirri were touched by the prey (Video 4, www.int-res.com/articles/suppl/a044p197_videos/).

As far as we know, these are the first published reports of critical fluid velocity values in protists. In metazoans, however, neuro-physiological responses to fluid velocity gradients on the order of $20 \mu \mathrm{m} \mathrm{s}^{-1}$ have been found in the raptorial copepod Labidocera madurae (Yen et al. 1992) and $36 \mu \mathrm{m} \mathrm{s}^{-1}$ in Undinula vulgaris (Lenz \& Hartline 1999); a similar ecological value of $40 \mu \mathrm{m} \mathrm{s}^{-1}$ was found in the raptorial copepod Oithona similis (Svensen \& Kiørboe 2000). This suggests that our estimates of critical fluid velocities, which ranged from 15 to $42 \mu \mathrm{m} \mathrm{s}^{-1}$, are realistic estimates of prey-generated fluid velocities typifying the planktonic world that elicit attack behavior in predators (see Table 3).

\section{Escape behavior in prey flagellates}

All 3 prey species demonstrated strong evasive reactions when they encountered the motionless Mesodinium pulex. However, some differences exist. The 2 dinoflagellates exhibited typical saltatory escape behaviors in undisturbed environments. This behavior is similar to the unprovoked saltatory behavior reported in ciliates (Tamar 1965). In contrast, Rhodomonas salina swam slowly and did not display spontaneous jumps. It was therefore surprising that this flagellate was able to increase its swimming speed dramatically upon contact with $M$. pulex. Remote predator detection followed by evasive reactions was studied in a prymnesiophyte and a dinophyte flagellate by Jakobsen (2002). In that study, it was suggested that the flagellate cell bodies were strained by the feeding current of a potential ciliate predator, similar to the situation outlined in Fig. 3b. In the present study, small prey approached a large motionless ciliate that appeared to be anchored. The anchored ciliate cell may have deformed the fluid field surrounding the motile flagellates (fluid field isoclines of the motile prey are shown in Fig. 1) in a fashion that deformed and thus alerted the cell membrane-bound mechanoreceptors of prey. Such rheotactically mediated escape behaviors may be a common phenomenon in small flagellates, prompting predators to develop structures to paralyze and fix prey prior to ingestion.

Mesodinium rubrum displays an oral ring of tentacles ending in triangular structures similar to the oral tentacles observed in M. pulex (Lindholm et al. 1988, Tamar 1992), and the prey appears fixed to the apical end of the oral cilia prior to ingestion (Yih et al. 2004). Ultrastructural aspects of $M$. rubrum, including the oral cilia, have previously been studied. Lindholm et al. (1988) found that $M$. rubrum were associated with extrusomes of a type termed 'toxicycts' (Hausmann \& Hülsmann 1996). Toxicysts may be involved in postcapture prey immobilization by $M$. pulex as well. We observed that Heterocapsa rotundata, once captured by $M$. pulex, remained fixed by the oral cilia for some time, indicating that the ciliate was using prey surface structure for prey recognition in a fashion similar to heliozoans (Sakaguchi et al. 2002). Such prey-specific cell surface structures may be absent in the membrane of Rhodomonas salina, explaining why R. salina was immobilized, but not successfully captured by the predatory ciliate (Video 3, www.int-res.com/articles/suppl/ a044p197_videos/). After being immobilized for approximately $1 \mathrm{~s}$, about half of the $R$. salina cells actively evaded the predator by jumping away. In the remaining encounters $R$. salina simply swam away unaffected.

Because toxicysts appear to be important in prey capture by Mesodinium pulex, the probability of missing a prey cell may increase with prey swimming speed. Thus, M. pulex may be unable to effectively immobilize and capture the fast-swimming Gymnodinium simplex, due to misfiring of toxicysts, leading to the low observed ingestion efficiency of $4 \%$ (Table 4 ).

For encounters in which Mesodinium pulex escaped from the fast-swimming dinoflagellate Gymnodinium simplex, the estimated critical fluid velocity was $95 \mu \mathrm{m}$ $\mathrm{s}^{-1}$. Assuming a sensor diameter of $18 \mu \mathrm{m}$ (cell body diameter, see Table 1), a critical deformation rate for escape of $95 \mu \mathrm{m} \mathrm{s}^{-1} / 18 \mu \mathrm{m}=5.3 \mathrm{~s}^{-1}$ is found. Behavioral aspects of $M$. pulex, including escape length, escape velocity and the critical deformation rate for escape, have previously been studied. Jakobsen (2001) found that M. pulex escaped with an average distance of $0.2 \mathrm{~cm}$ at a speed of $0.21 \mathrm{~cm} \mathrm{~s}^{-1}$. Moreover, a critical deformation rate for escape of $2.4 \mathrm{~s}^{-1}$ was identified. This value is exceeded by the critical deformation rate generated by swimming G. simplex, indicating that the combination of cell size and fast swimming in G. simplex is sufficiently strong to move the COM of M. pulex and strain the ciliate cell. That is, the fluid motion generated by G. simplex can mimic the fluid motion of a potential predator. 


\section{Final remarks}

Here, we have shown that the raptorial ambushfeeding ciliate Mesodinium pulex uses prey-generated fluid velocity gradients to detect its prey at a certain distance. The prey, in turn, detect $M$. pulex from the deformation of the fluid velocity gradients that surround the motile prey cells. These signals do not translate very far and are therefore useless for the detection of prey at scales much longer than a few body lengths. Thus, at scales larger than a few prey body lengths, $M$. pulex is hydromechanically inefficient; chemical cues emitted by prey are doubtless important for the detection of prey patches over these longer distances as described for other ciliates (Buskey \& Stoecker 1988, 1989).

Rheotactic ambush-feeding protists such as Mesodinium pulex are adapted to motionless feeding, thus minimizing fluid mechanical disturbance. Such fluid mechanical signals could otherwise alarm rheotactic predators or prey. In contrast, motionless feeding minimizes encounters with prey, so that alternative mechanisms are required to compensate for periods without prey encounters. The congener $M$. rubrum has solved this by hosting chloroplasts sequestered from its prey (Gustafson et al. 2000). M. pulex does not appear to sequester prey chloroplasts, and other means for survival, such as resistance to starvation, may be used instead.

The outcome of an encounter between Mesodinium pulex and its prey and predators, and most likely of many other protist predator-prey interactions, is driven by complex interactions among cell sizes, swimming velocities, prey behaviors and chemical cues. As for better-studied modes of interaction, hydromechanical signaling probably also contributes to structuring the microbial food web, including the diversity of morphologies and behaviors exhibited by flagellates and their protistan predators.

Acknowledgements. This work was supported by an NSF REU grant to Shannon Point Marine Center and NSF Grant OCE 0002479 to S.L.S. We are indebted to T. Fenchel, A. Visser and T. Kiørboe, who provided insightful comments on earlier drafts of this manuscript that significantly improved the final paper. This work is based on motion analysis of video recordings. Representative examples of behavioral interactions can be found at: www.int-res.com/articles/suppl/ a044p197_videos/.

\section{LITERATURE CITED}

Batchelet E (1981) Circular statistics in biology. Academic Press, London

Buskey EJ, Stoecker DK (1988) Locomotory patterns of the planktonic ciliate Favella sp.: adaptations for remaining within food patches. Bull Mar Sci 43:783-796
Buskey EJ, Stoecker DK (1989) Behavioral responses of the marine tintinnid Favalla sp. to phytoplankton: influence of chemical, mechanical and photic stimuli. J Exp Mar Biol Ecol 123:1-16

De Peyer JE, Machemer H (1978) Hyperpolarization and depolarizing mechanoreceptor potentials in Stylonychia. J Comp Physiol 127:255-266

Feigenbaum D, Reeve MR (1977) Prey detection in Chaetognatha - response to a vibrating probe and experimentaldetermination of attack distance in large aquaria. Limnol Oceanogr 22:1052-1058

Fenchel T, Blackburn N (1999) Motile chemosensory behaviour of phagotrophic protists: mechanisms for and efficiency in congregating at food patches. Protist 150:325-336

Fenchel T, Jonsson PR (1988) The functional biology of Strombidium sulcatum, a marine oligotrich ciliate (Ciliophora, Oligotrichina). Mar Ecol Prog Ser 48:1-15

Gilbert JJ (1994) Jumping behaviour in the oligotrich ciliates Strobilidium velox and Halteria grandinella, and its significance as defence against rotifer predators. Microb Ecol 27:189-200

Görtz HD (1982) The behaviour and fine structure of the dorsal bristles of Euplotes minuta, E. aediculatus, and Stylnochia mytilus (Ciliata, Hypotrichida). J Protozool 29: 353-359

Gustafson DJ, Stoecker DK, Johnson MD, Van Heukelem WF, Sneider K (2000) Cryptophyte algae are robbed of their organelles by the marine ciliate Mesodinium rubrum. Nature 405:1049-1052

Hausmann K, Hülsmann N (1996) Protozology. Georg Thieme Verlag, Stuttgart

Jakobsen HH (2001) Escape response of planktonic protists to fluid mechanical signals. Mar Ecol Prog Ser 214:67-78

Jakobsen HH (2002) Escape of protists in predator-generated feeding currents. Aquat Microb Ecol 26:271-281

Jakobsen HH, Halvorsen E, Hansen BW, Visser AW (2005) The effects of food concentrations on prey motility on feeding Acartia tonsa and Temora longicornis: the importance of feeding modes. J Plankton Res 27:775-785

Jonsson PR, Tiselius P (1990) Feeding behaviour, prey detection and capture efficiency of copepod Acartia tonsa feeding on planktonic ciliates. Mar Ecol Prog Ser 60:35-44

Kerfoot WC (1978) Combat between predatory copepods and their prey: Cyclops, Epischoura and Bosminia. Limnol Oceanogr 23:1089-1102

Kiørboe T, Visser AW (1999) Predation and prey perception in copepods due to hydromechanical signals. Mar Ecol Prog Ser 179:81-95

Lenz PH, Hartline DK (1999) Reaction times and force production during escape behavior of a calanoid copepod, Undinula vulgaris. Mar Biol 133:249-258

Lindholm T, Lindross P, Mork AC (1988) Ultrastructure of the photosynthetic ciliate Mesodinium rubrum. BioSystems 21:141-149

Machemer H, Deitmer JW (1985) Mechanoreception in ciliates. In: Ottoson D (ed) Progress in sensory physiology. Springer, Berlin, p 81-118

Machemer H, Machemer-Röhnisch S (1984) Mechanical and electric correlates of mechanoreceptor activation of the ciliated tail in Paramecium. J Comp Physiol 154:273-278

Naitoh Y, Eckert R (1969) Ionic mechanisms controlling behavioral responses of Paramecium to mechanical stimulation. Science 164:963-965

Sakaguchi M, Murakami H, Suzaki T (2002) Involvement of a 40-kDa glycoprotein in food recognition, prey capture, and induction of phagocytosis in the protozoon Actinophrys sol. Protist 152:33-41 
Stoecker DK, Capuzzo JM (1990) Predation on protozoa: its importance to zooplankton. J Plankton Res 12:891-908

Stoecker DK, Gallager SM, Langdon CJ, Davis LH (1995) Particle capture by Favella sp. (Ciliata, Tintinnina). J Plankton Res 17:1105-1124

Strom SL (2002) Novel interactions between phytoplankton and microplankton: the influence on the coupling between growth and grazing rates in the sea. Hydrobiologia 148:41-54

Svensen C, Kiørboe T (2000) Remote prey detection in Oithona similis: hydromechanical vs. chemical cues. J Plankton Res 22:1155-1166

Tamar H (1965) The culture, structure, and locomotion of Halteria grandinella. Acta Protozool 3:165-172

Tamar H (1992) Four marine species of Mesodinium (Ciliophora: Mesodiniidae). II. Mesodinium pulex CLAPH. \& LACHM., 1858. Arch Protistenkd 141:284-303

Tang KW, Jakobsen HH, Visser AW (2001) Phaeocystis glo-

Editorial responsibility: Urania Christaki, Wimereux, France bosa (Prymnesiophyceae) and the planktonic food web: feeding, growth, and trophic interactions among grazers. Limnol Oceanogr 46:1860-1870

Tiselius P, Jonsson PR, Kaartvedt S, Olsen EM, Joerstad T (1997) Effects of copepod foraging behavior on predation risk: an experimental study of the predatory copepod Pareuchaeta norvegica feeding on Acartia clausi and A. tonsa (Copepoda). Limnol Oceanogr 42:164-170

Verity PG (1991) Feeding in planktonic protozoans: evidence for non-random acquisition of prey. J Protozool 38:69-76

Visser AW (2001) Hydromechanical signals in the plankton. Mar Ecol Prog Ser 222:1-24

Yen J, Lenz PH, Gassie DV, Hartline DK (1992) Mechanoreception in marine copepods: electrophysiological studies on the first antennae. J Plankton Res 14:495-512

Yih WH, Kim HS, Jeong HJ, Myung G, Kim YG (2004) Ingestion of cryptophyte cells by the marine photosynthetic ciliate Mesodinium rubrum. Aquat Microb Ecol 36:165-170

Submitted: November 10, 2005; Accepted: June 9, 2006

Proofs received from author(s): August 14, 2006 